\title{
The role of tissue elasticity in the differential diagnosis of benign and malignant breast lesions using shear wave elastography
}

\author{
Hui Yang ${ }^{1}$, Yongyuan $\mathrm{Xu}^{1}$, Yanan Zhao ${ }^{1}$, Jing Yin ${ }^{1}$, Zhiyi Chen ${ }^{2}$ and Pintong Huang ${ }^{1^{*}}$ (D)
}

\begin{abstract}
Background: Elastography is a promising way to evaluate tissue differences regarding stiffness, and the stiffness of the malignant breast lesions increased at the lesion margin. However, there is a lack of data on the value of the shear wave elastography (SWE) parameters of the surrounding tissue (shell) of different diameter on the diagnosis of benign and malignant breast lesions. Therefore, the purpose of our study was to evaluate the diagnostic performance of shell elasticity in the diagnosis of benign and malignant breast lesions using SWE.

Methods: Between September 2016 and June 2017, women with breast lesions underwent both conventional ultrasound (US) and SWE. Elastic values of the lesions peripheral tissue were determined according to the shell size, which was automatically drawn along the edge of the lesion using the following software guidelines: (1): $1 \mathrm{~mm}$; (2): $2 \mathrm{~mm}$; and (3): $3 \mathrm{~mm}$. Quantitative elastographic features of the inner lesions and shell, including the elasticity mean $\left(E_{\text {mean }}\right)$, elasticity maximum $\left(E_{\max }\right)$, and elasticity minimum $\left(E_{\min }\right)$, were calculated using an online-available software. The receiver operating characteristic curves (ROCs) of the elastographic features was analyzed to assess the diagnostic performance, and the area under curve (AUC) of each elastographic feature was obtained. Logistic regression analysis was used to predict significant factors of malignancy, permitting the design of predictive models.
\end{abstract}

Results: This prospective study included 63 breast lesions of 63 women. Of the 63 lesions, 33 were malignant and 30 were benign. The diagnostic performance of $E_{\text {max-3shell }}$ was the highest ( $A U C=0.76$ ) with a sensitivity of $60.6 \%$ and a specificity of $83.3 \%$. According to stepwise logistic regression analysis, the $E_{\text {max-3shell }}$ and the $E_{\text {min-3shell }}$ were significant predictors of malignancy $(p<0.05)$. The AUC of the predictive equation was 0.86 .

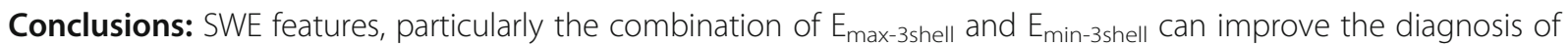
breast lesions.

Keywords: Breast, Elastography, Shear wave elastography, Ultrasonography

\footnotetext{
*Correspondence: huangpintong@zju.edu.cn

'Department of Ultrasound in Medicine, The Second Affiliated Hospital of

Zhejiang University School of Medicine, Hangzhou 310009, China

Full list of author information is available at the end of the article
}

(c) The Author(s). 2020 Open Access This article is licensed under a Creative Commons Attribution 4.0 International License, which permits use, sharing, adaptation, distribution and reproduction in any medium or format, as long as you give appropriate credit to the original author(s) and the source, provide a link to the Creative Commons licence, and indicate if changes were made. The images or other third party material in this article are included in the article's Creative Commons licence, unless indicated otherwise in a credit line to the material. If material is not included in the article's Creative Commons licence and your intended use is not permitted by statutory regulation or exceeds the permitted use, you will need to obtain permission directly from the copyright holder. To view a copy of this licence, visit http://creativecommons.org/licenses/by/4.0/ The Creative Commons Public Domain Dedication waiver (http://creativecommons.org/publicdomain/zero/1.0/) applies to the data made available in this article, unless otherwise stated in a credit line to the data. 


\section{Background}

Breast cancer is a global health burden and a leading cause of death in females worldwide [1]. Ultrasonography (US), as an adjunct technique for palpable or mammographically detected breast lesions, permits high sensitivity (typically $\geq 90 \%$ ) characterization of breast abnormalities [2, 3]. However, the US displays low specificity, thereby leading to unnecessary benign biopsies [46]. To improve the accuracy of the differential diagnosis of benign and malignant breast lesions, US elastography has been proposed as a non-invasive alternative. US elastography is an imaging technique that can be used to assess the stiffness or elasticity of breast masses, which is analogous to clinical palpation with US for a mass. The distinction between clinical palpation and elastography is that the former allows only a subjective judgment of the stiffness of a lesion, while elastography assesses tissue-specific differences in stiffness and/or elasticity, as lesions with an abnormal internal structure have altered elasticity [7-12] . For the assessment of breast lesions, two types of elastography are currently used, namely strain elastography (SE) and shear wave elastography (SWE). For SE, the major shortcomings are operatordependency and a lack of quantitative information regarding the elasticity modulus. SWE provides quantitative values for the Young elastic modulus (in kilopascals) of tissues by imaging shear wave propagation, thus avoiding the shortcomings of SE $[13,14]$. SWE has been shown to display high inter-and intra-observer reproducibility for both qualitative and quantitative parameters $[15,16]$. In recent years, some studies had shown the stiffness of the tissue surrounding (shell) of the malignant breast lesions had been shown to be higher than that of benign breast lesions $[17,18]$. To date, to our knowledge, the value of the SWE parameters of the different shell sizes on the diagnosis of benign and malignant breast lesions has not been assessed. In this prospective study, we hypothesized that these parameters might permit the differentiation between benign and malignant breast lesions. Therefore, the purpose of this study was to evaluate the diagnostic performance of shell elasticity in the diagnosis of benign and malignant breast lesions SWE.

\section{Methods}

\section{Patients}

This prospective study was approved by our institutional review board (IR001097). Written informed consent was obtained from all patients before examination.

From September 2016 to June 2017, a total of 178 consecutive patients with breast lesions who underwent the conventional US and SWE examination in our hospital, which were palpable by oncologists or visible on the conventional US, were enrolled in this study. The inclusion criteria were as follows: (1) breast lesions were palpable by an oncologist or were visible on the conventional US; (2) no treatment such as breast surgery, radiotherapy or chemotherapy was performed prior to enrollment. One hundred fifteen patients were excluded because of the following reasons: (1) lesions with treatments before enrollment; (2) lesions with BI-RADS scores less than 3 based on the conventional US; (3) lack of normal breast tissues (less than $3 \mathrm{~mm}$ in thickness) surrounding the enormous lesions for the elastic image and (4) no final histological results. A flowchart for the patients selection process was shown in Fig. 1. For evaluation, only 1 lesion with the highest BI-RADS category in each patient was selected. If multiple lesions were in the same BI-RADS category, the lesion with the largest diameter was selected.

\section{Ultrasound equipment}

SWE and the conventional US were obtained using a Resona 7 diagnostic US system (Mindray Medical International, Shenzhen, China) equipped with an L14-5 linear transducer. The diagnostic system was equipped with a unique shell quantification toolbox, which was applied to measure the stiffness of the margin $(0.5 \sim 9$ $\mathrm{mm}$ ) surrounding the lesion in $0.5 \mathrm{~mm}$ increments.

\section{Image evaluation}

Conventional US and SWE examinations were performed by a single radiologist (X.Y.Y.) with 20 years of experience in breast US. Quantitative SWE parameters were assessed by Y.H. (2 years of experience in breast US), and Z.Y.N. (3 years of experience in breast US) who were blinded to the BI-RADS score. Lesions for transverse and longitudinal US images were obtained in the supine position. Based on the gray-scale US image, all conventional US features of the lesions were assessed by using the terminology of the US BI-RADS lexicon. After a careful description of the lesions, a final BI-RADS assessment category was assigned. According to BI-RADS categories: BI-RADS 2 was benign; for BI-RADS 3, ultrasound of the breast revealed probable benign characteristics; BI-RADS 4a, $4 \mathrm{~b}$ and $4 \mathrm{c}$ represented a low, moderate, and high suspicion of malignancy, respectively; BI-RADS 5 and BI-RADS 6 were highly suggestive of malignancy. According to the guidelines of the American Society of Radiology, a biopsy is recommended for breast lesions with BI-RADS 4a or higher. Follow-up is recommended for BI-RADS 3. The following steps were performed for correct elastic image acquisition: US examinations produced standard B-mode gray-scale images, and the lesions were placed in the center of the screen. During SWE measurements, the transducer was positioned perpendicular, and the pressure of the transducer was maintained to a minimum. 


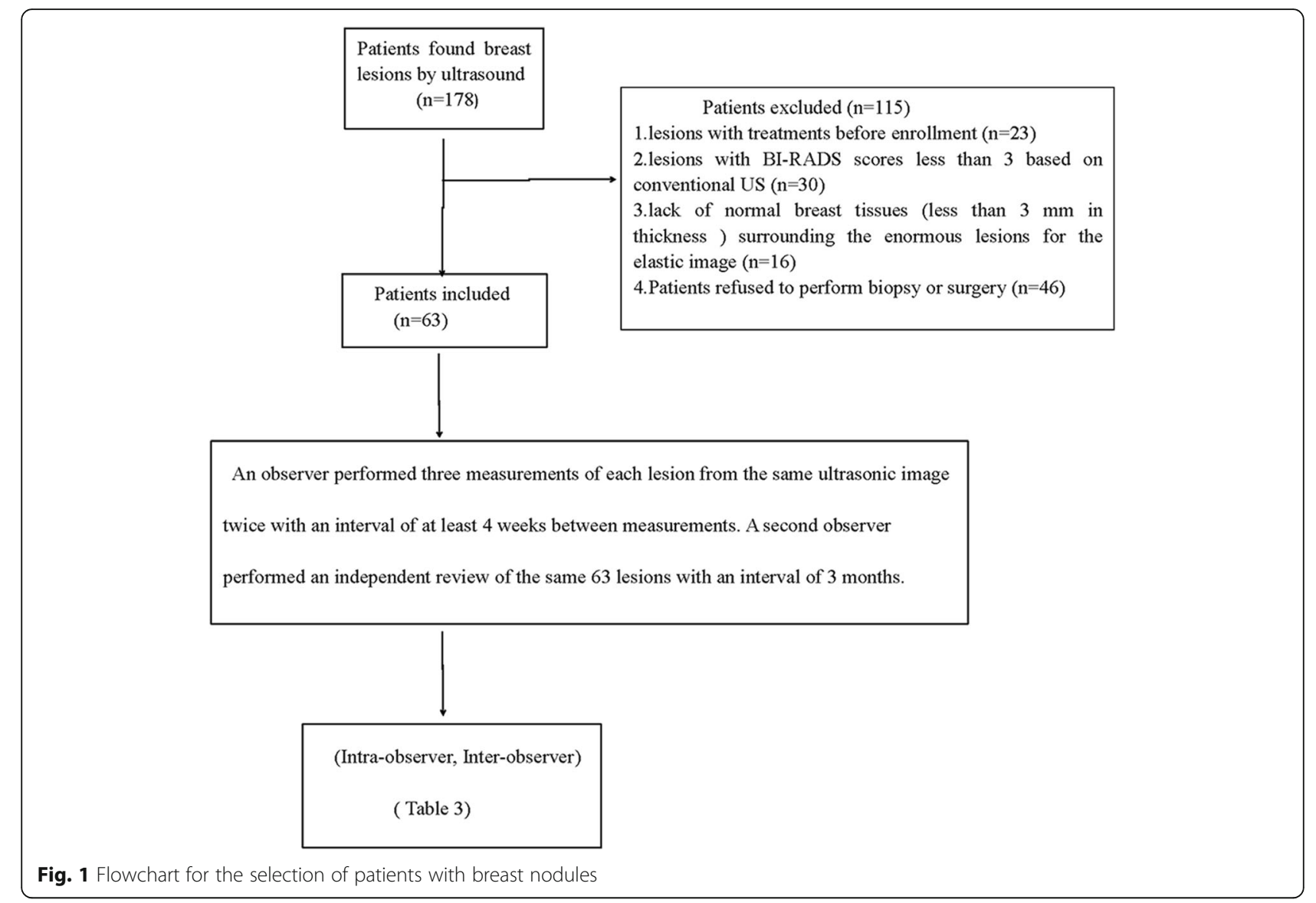

Elastic images were obtained while patients held their breath. The reliability of the SWE images was assessed using a shear wave quality mode: the Quality Control Chart (QCC). When the color in the QCC was uniform, the SWE images were considered of high quality. When an imaging plane with the largest diameter of a breast lesion was located on conventional US images, a square region of interest (ROI) was set and adjusted to include the entire breast lesion and subcutaneous fat layer to the chest muscle layer for SWE acquisition. SWE images and Bmode conventional US were simultaneously displayed on a monitor. For SWE measurements, stiffness was quantified using the Young modulus $(0-140 \mathrm{kPa})$. The dynamic model was selected, and quality control charts were simultaneously displayed to indicate good shear wave qualities and to ensure that no obvious artifacts were analyzed on the elastic modulus map. The ROI varied according to the size and shape of the breast lesion. Once the image stabilized, the ROI was drawn around the lesion. The ROI of the surrounding tissue was measured using the shell function according to shell size. A series of quantitative elastographic features of the inner lesion $\left(E: E_{\text {mean }}, E_{\max }, E_{\min }\right)$, the elastic mean of the shell size $1,2,3 \mathrm{~mm}\left(\mathrm{E}_{\text {mean-shell }}\right.$ : $E_{\text {mean-1shell }}, E_{\text {mean-2shell }}, E_{\text {mean-3shell }}$, the elastic maximum of the shell size 1, 2, $3 \mathrm{~mm}\left(\mathrm{E}_{\text {max-shell }} \mathrm{E}_{\text {max-1shell }}, \mathrm{E}_{\text {max-2shell }}\right.$,
$\left.E_{\max -3 \text { shell }}\right)$, and the elastic minimum of the shell size $\left(E_{\text {min-shell }}: E_{\text {min-.1shell, }} E_{\text {min-2shell }}, E_{\text {min-3shell }}\right)$ were calculated (Figs. 2 and 3).

\section{Observer variability evaluation}

Intra-observer agreement was assessed by a radiologist (Y.H) who performed three measurements of each lesion from the same ultrasonic image twice with an interval of at least 4 weeks between measurements. To assess interobserver variability, a second observer (Z.Y.N), who was blinded to the previous US and histopathological results, performed an independent review of the same 63 lesions with an interval of 3 months. Agreements between the two measurements by the different observers were evaluated.

\section{Histopathological examination}

Histopathological examination was used as the reference standard for all patients. Histopathological diagnosis was performed by an experienced pathologist ( $\geq 15$ years' experience) who was blinded to the ultrasound results.

\section{Statistical analysis}

Statistical analyses were performed using SPSS, version 17.0 (SPSS, Chicago, IL, USA). ROC analysis was performed by using MedCalc for Windows, version 13.1.2.0 


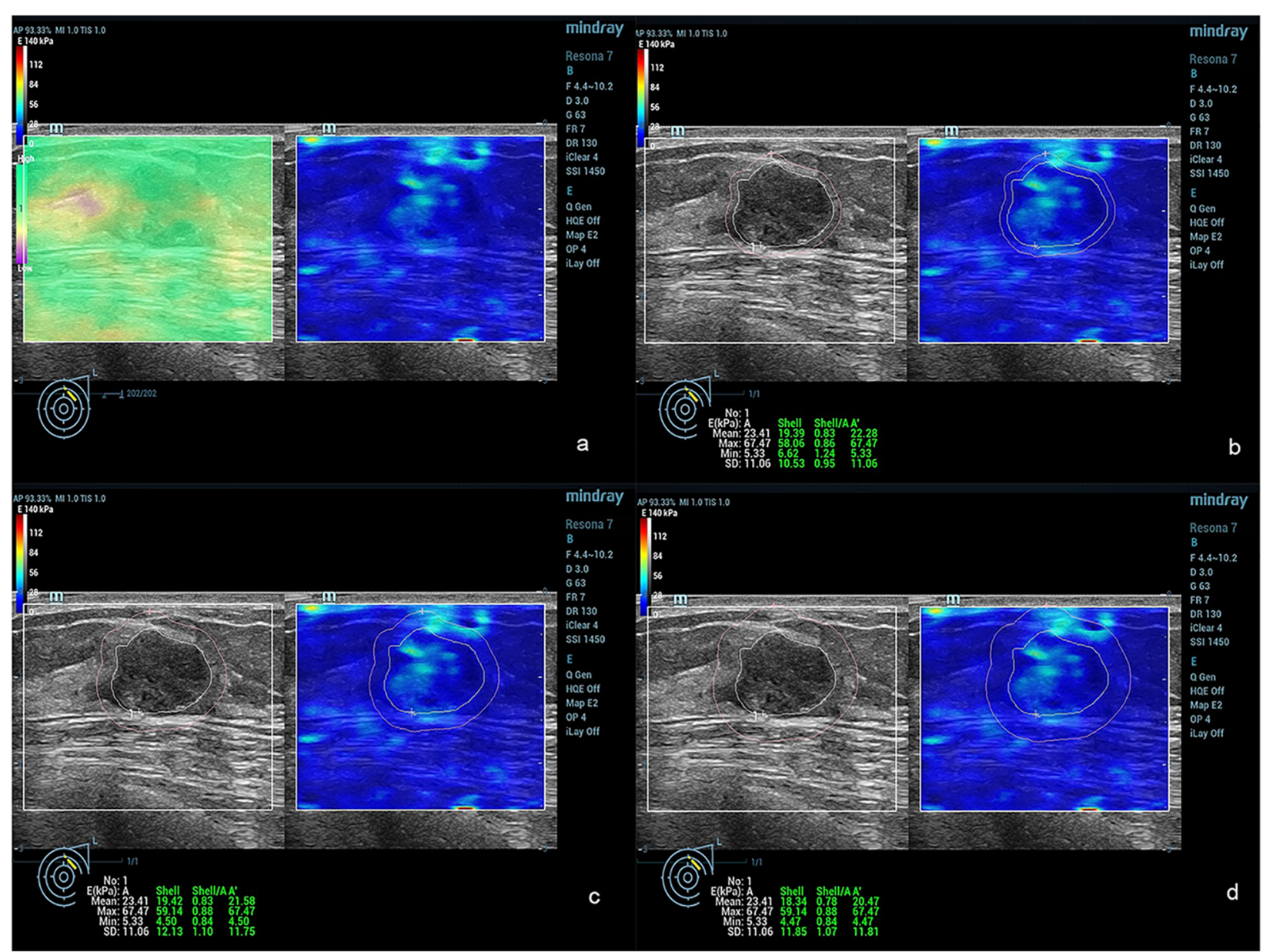

Fig. 2 Fibroadenoma in a female patient. The $E_{\max }$ and $E_{\min }$ values of the breast lesion were $67.47 \mathrm{kPa}$ and $5.33 \mathrm{kPa}$, respectively. a: SWE quality control with no obvious artifacts; $\mathbf{b}$ : The shell included $1 \mathrm{~mm}$ peripheral tissue around the breast lesion contour on the SWE image. The values of $E_{\text {max-1shell, }} E_{\text {mean-1shell }}$ and $E_{\text {min-1shell }}$ were $58.06 \mathrm{kPa}, 19.39 \mathrm{kPa}$ and $6.62 \mathrm{kPa}$; $\mathbf{c}$. The shell included $2 \mathrm{~mm}$ peripheral tissue around the breast lesion on the SWE image. The values of $\mathrm{E}_{\text {max-2shell, }} \mathrm{E}_{\text {mean-2shell }}$ and $\mathrm{E}_{\text {min-2shell }}$ were $59.14 \mathrm{kPa}, 19.42 \mathrm{kPa}$, and $4.5 \mathrm{kPa}$; $\mathbf{c}$ : The shell included $3 \mathrm{~mm}$ peripheral

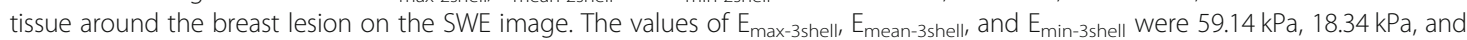
$4.47 \mathrm{kPa}$, respectively

(MedCalc Software, Mariakerke, Belgium). Optimal cutoff values were determined through the Youden index (maximum of sensitivity + specificity -1 ). The independent samples t-test was used to compare the quantitative SWE values. The McNemar test was employed for the paired comparison of proportions (sensitivity, specificity, positive prediction, and negative prediction values). A step-wise multivariate logistic regression analysis was used to identify risk factors and risk models for malignancy. Intraclass correlation coefficients (ICCs) were used to assess intraand inter-observers. A $p$ value less than 0.05 was considered statistically significant differences.

\section{Results}

\section{Study population}

A total of 63 patients with breast lesions were enrolled in this study. Among them, 33 lesions were malignant and 30 were benign. The age of the included patients ranged from 19 to 86 years, with an average age of 46.8 years. The mean age of the benign and malignant patients included in our study was $38.5 \pm 14.7$ years (range, $19-86$ years) and $54.4 \pm 12.5$ years (range, 30 80 years), respectively. The maximal diameter of the lesions from the conventional US was $20.0 \pm 8.6 \mathrm{~mm}$ (range: $5.1-51.3 \mathrm{~mm}$ ). The mean diameter $\pm \mathrm{SD}$ of malignant and benign nodules were $20.3 \pm 7.5 \mathrm{~mm}$ and $19.6 \pm 9.7 \mathrm{~mm}$, respectively. No significant differences were observed in the size of the benign and malignant breast lesions $(p>0.05)$. Ultrasound-guided core needle biopsies were performed in all lesions, and 59 lesions underwent surgery. From pathological assessments, the malignant lesions included mucinous carcinoma $(n=1)$, infiltrating ductal carcinoma $(n=25)$, invasive lobular carcinoma $(n=1)$, papillary carcinoma 


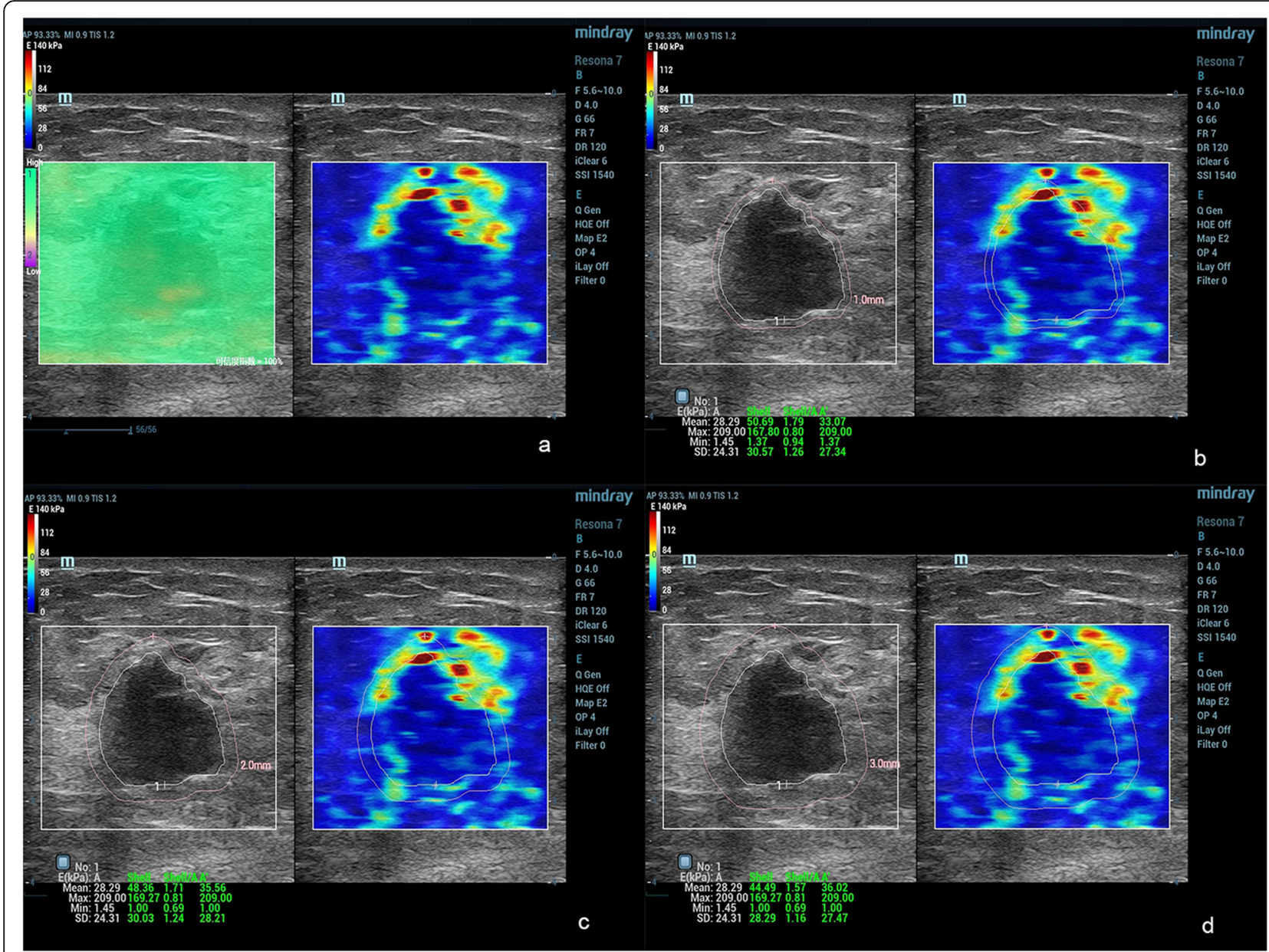

Fig. 3 Infiltrating ductal carcinoma in a female patient. The $E_{\max }$ and $E_{\min }$ values of the breast lesion were $209.00 \mathrm{kPa}$ and $1.45 \mathrm{kPa}$, respectively. a: SWE quality control with no obvious artifacts; $\mathbf{b}$ : The shell included $1 \mathrm{~mm}$ peripheral tissue around the breast lesion on the SWE image. The values of $E_{\text {max-1 shell, }} E_{\text {mean-1 shell }}$ and $E_{\text {min-1shell }}$ were $167.8 \mathrm{kPa}, 50.69 \mathrm{kPa}$ and $1.37 \mathrm{kPa}$; $\mathbf{c}$ : The shell included $2 \mathrm{~mm}$ peripheral tissue around the breast lesion on the SWE image. The values of $\mathrm{E}_{\text {max-2shell, }} \mathrm{E}_{\text {mean-2shell }}$ and $\mathrm{E}_{\text {min-2shell }}$ were $169.27 \mathrm{kPa}, 48.36 \mathrm{kPa}$, and $1.00 \mathrm{kPa}$; $\mathbf{c}$ : The shell included 3 $\mathrm{mm}$ peripheral tissue around the breast lesion on the SWE image. The values of $E_{\text {max }-3 \text { shell, }} E_{\text {mean-3shell, }}$ and $E_{\text {min-3shell }}$ were $169.27 \mathrm{kPa}$, $44.49 \mathrm{kPa}$, and $1.00 \mathrm{kPa}$

$(n=1)$, and ductal carcinoma in situ $(n=5)$. Benign diagnoses were as follows: fibroadenoma $(n=18)$, fibroadenomatous hyperplasia $(n=3)$, papilloma $(n=$ $3)$, inflammation $(n=2)$, and adenosis $(n=4)$. Histopathological results of the benign and malignant tumors are summarized in Table 1. For the conventional ultrasound BI-RADS category, the numbers of category $3,4 \mathrm{a}, 4 \mathrm{~b}, 4 \mathrm{c}, 5$, and 6 cases were $10 /$ 63 (15.9\%), 11/63 (17.5\%), $11 / 63$ (17.5\%), 12/63 (19.0\%), 13/63 (20.6\%), and 6/63 (9.5\%), respectively. The malignancy rates were $10 \%(1 / 10)$ for category 3 , $0.0 \%(0 / 11)$ for category $4 a, 36.4 \%(4 / 11)$ for category $4 b, 75.0 \%$ (9/12) for category 4c, 100.0\% (13/13) for category 5, and $100.0 \%(6 / 6)$ for category 6. Category 4a had the lowest likelihood of malignancy, while categories 5 and 6 had the highest likelihood. The optimal cutoff was between category $4 \mathrm{a}$ and category $4 \mathrm{~b}$.

\section{Diagnostic performance of the quantitative SWE features}

Diagnostic performance of SWE parameters of the shell $\left(\mathbf{E}_{\text {shell }}\right)$ The elastographic values of the shell ( $E_{\text {mean-shell }}, E_{\text {max-shell }}$ and $\left.E_{\text {min-shell }}\right)$ significantly differed between benign and malignant breast lesions. The $\mathrm{E}_{\text {min-- }}$ shell values were significantly lower in malignant lesions compared to benign lesions $(p<0.05)$. The values of $E_{\text {max-3shell }}$ and $E_{\text {max-2shell }}$ for invasive breast carcinomas were significantly higher than those of non-invasive carcinomas $(p<0.05)$. The elastographic values of the shell were shown in Table 2, and the results are depicted by box plots (Fig. 4) for malignant and begin lesions. Amongst the $\mathrm{E}_{\text {shell }}$ parameters for the lesions with BIRADS scores of 3 or greater, $E_{\max -3 \text { shell }}$ had the highest AUC: 0.76 (95\% CI $0.63,0.86)$ with a sensitivity of $60.6 \%$, a specificity of $83.3 \%$, positive predictive values of 
Table 1 Summary of pathologic findings and performance of conventional ultrasound

\begin{tabular}{|c|c|c|c|c|c|c|c|}
\hline \multirow[t]{2}{*}{ Histopathological results } & \multicolumn{7}{|c|}{ Conventional US BI-RADS category } \\
\hline & No of lesions (\%) & 3 & $4 A$ & 4B & $4 C$ & 5 & 6 \\
\hline Benign & $30(47.6)$ & & & & & & \\
\hline Fibroadenoma & $18(60.0)$ & 7 & 9 & 1 & 1 & 0 & 0 \\
\hline Fibroadenomatous Hyperplasia & $3(10.0)$ & 1 & 0 & 1 & 1 & 0 & 0 \\
\hline Papilloma & $3(10.0)$ & 1 & 0 & 2 & 0 & 0 & 0 \\
\hline Inflammation & $2(6.7)$ & 0 & 1 & 1 & 0 & 0 & 0 \\
\hline Adenosis & $4(13.3)$ & 0 & 1 & 2 & 1 & 0 & 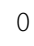 \\
\hline Malignant & $33(52.4)$ & & & & & & \\
\hline Mucinous Carcinoma & $1(3.0)$ & 0 & 0 & 1 & 0 & 0 & 0 \\
\hline Infiltrating ductal carcinoma & $25(75.8)$ & 1 & & 3 & 5 & 11 & 5 \\
\hline Invasive lobular carcinoma & $1(3.0)$ & 0 & 0 & 0 & 0 & 1 & 0 \\
\hline Papillary carcinoma & $1(3.0)$ & 0 & 0 & 0 & & 1 & 0 \\
\hline Ductal carcinoma in situ & $5(15.2)$ & 0 & 0 & 0 & 4 & & 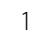 \\
\hline
\end{tabular}

$80.0 \%$, and negative predictive values of $65.8 \%$. No significant differences were observed in the AUCs amongst the elastic parameters. The specificity and positive predictive values of the $\mathrm{E}_{\max -3 s h e l l}$ were higher compared to that of other elastic parameters $(p<0.05)$.

Diagnostic performance of the SWE parameters of the inner lesions $T$ The $E_{\max }$ and $E_{\min }$ values significantly differed between benign and malignant breast lesions. The $\mathrm{E}_{\mathrm{min}}$ values were significantly lower in malignant lesions compared to benign lesions $(p<0.05)$. The AUC of the $E_{\max }$ and $E_{\min }$ were $0.68(95 \% \mathrm{CI} 0.56,0.80)$ and 0.71 (95\% CI 0.58, 0.82) for the lesions with BI-RADS scores of 3 or greater. No significant differences were observed between the AUCs of the $E_{\max }$ and $E_{\min }$. The sensitivity, specificity, positive prediction values, and negative prediction values of $E_{\max }$ and $E_{\min }$ were 66.7, 70, 71.0, 65.6, and 87.9\%, 53.3, 67.4, 80\%, respectively. The AUC, sensitivity, specificity, positive prediction value (PPV), negative prediction value (NPV) of the $E$, and $E_{\text {shell }}$ were summarized in Table 2.

\section{Multivariate logistic regression analysis}

Univariate analysis showed that the $E_{\text {shell }}, E_{\max }$ and $E_{\min }$ values significantly differed for the prediction of benign and malignant breast lesions. The elastic parameters were further analyzed using step-wise multivariate logistical regression, and upon logistical regression analysis, the $E_{\text {max-3shell }}$ and $E_{\text {min-3shell }}$ were significant independent predictors of malignancy with Odds Ratios (OR) of 1.02 (95\% CI 1.009-1.037; $p<0.05)$ and $0.65(95 \%$ CI $0.494-$ $0.853 ; p<0.05)$, respectively. The stability of multivariate

Table 2 Quantitative elastic features of the inner and peripheral tissue of the lesions

\begin{tabular}{|c|c|c|c|c|c|c|c|c|}
\hline & \multirow{2}{*}{$\begin{array}{l}\text { Benign } \\
\text { [Mean] }(\mathrm{kPa})\end{array}$} & \multicolumn{7}{|l|}{ Malignant } \\
\hline & & [Mean] (kPa) & Sensitivity (\%) & Specificity (\%) & PPV (\%) & NPV (\%) & AUC $(95 \% \mathrm{Cl})$ & $p$ Value \\
\hline$E_{\max }$ & 115.81 & 154.72 & 66.7 & 70 & 71.0 & 65.6 & $0.68(0.56,0.80)$ & 0.037 \\
\hline$E_{\min }$ & 6.06 & 3.05 & 87.9 & 53.3 & 67.4 & 80.0 & $0.71(0.58,0.82)$ & 0.004 \\
\hline$E_{\max -3 \text { shell }}$ & 112.45 & 169.74 & 60.6 & 83.3 & 80.0 & 65.8 & $0.76(0.63,0.86)$ & 0.000 \\
\hline$E_{\text {mean-3shell }}$ & 29.77 & 38.84 & 84.8 & 60.0 & 70.0 & 78.3 & $0.73(0.61,0.84)$ & 0.006 \\
\hline$E_{\text {min-3shell }}$ & 4.89 & 2.68 & 78.8 & 66.7 & 72.0 & 74.0 & $0.73(0.61,0.84)$ & 0.002 \\
\hline$E_{\max -2 \text { shell }}$ & 112.51 & 167.07 & 78.8 & 66.7 & 72.2 & 74.1 & $0.75(0.62,0.85)$ & 0.001 \\
\hline$E_{\text {mean-2shell }}$ & 32.28 & 37.15 & 60.6 & 83.3 & 80.0 & 65.8 & $0.70(0.58,0.81)$ & 0.014 \\
\hline$E_{\text {min-2shell }}$ & 5.41 & 3.08 & 72.7 & 73.3 & 75.8 & 73.3 & $0.73(0.60,0.83)$ & 0.002 \\
\hline$E_{\max -1 \text { shell }}$ & 107.27 & 151.15 & 66.7 & 70.0 & 71.0 & 65.6 & $0.70(0.57,0.81)$ & 0.004 \\
\hline$E_{\text {mean-1shell }}$ & 33.67 & 41.92 & 57.6 & 80.0 & 76.0 & 63.2 & $0.70(0.55,0.79)$ & 0.017 \\
\hline$E_{\text {min-1shell }}$ & 6.51 & 3.99 & 63.6 & 76.7 & 75.0 & 65.7 & $0.70(0.57,0.80)$ & 0.026 \\
\hline
\end{tabular}

Abbreviations: PPV positive predictive value, NPV negative predictive value, AUC the area under the receiver operating characteristic curve $p$-Value indicates that there is significantly different between those values of overall benign and malignant breast lesions 

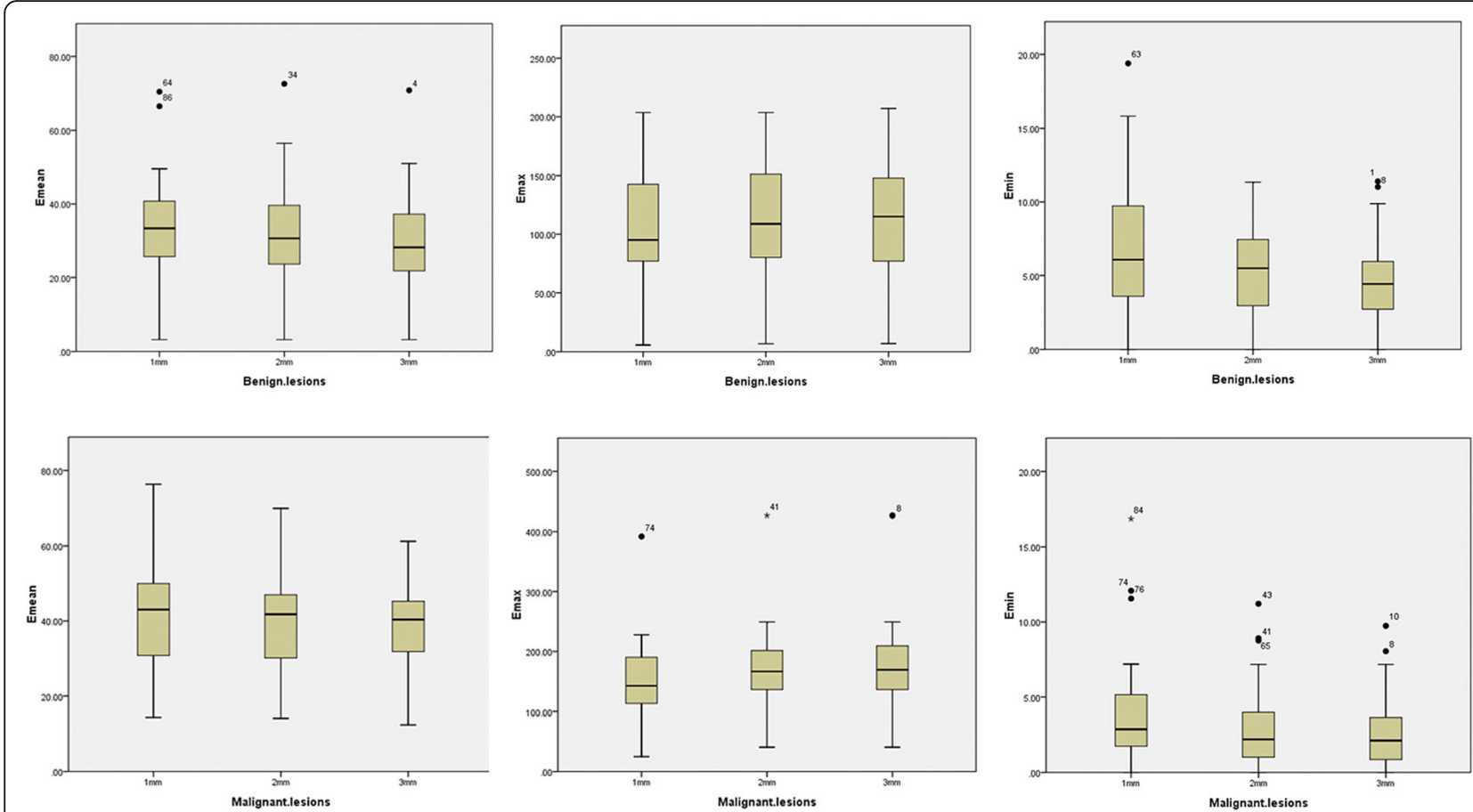

Fig. 4 Box and whisker plots of the mean elasticity, maximum elasticity, and minimum elasticity values at 1, 2, and 3 mm of the shell in both malignant (a) and benign (b) lesions

logistic regression models was tested by CrossValidation in Python, the training/testing split is $80 \%$ / $20 \%$, we assigned $80 \%$ of patients as the training set, and the remaining $20 \%$ used the test set, this procedure was repeated for twice, the recall (recall $=\mathrm{TP} / \mathrm{TP}+\mathrm{FN}$ ) were 0.83 and 0.88 respectively, the AUC were 0.85 and 0.84 respectively, the result indicated that the predictive model is reliable. The AUC of the predictive model was significantly higher compared to that of the $E_{\text {max-3shell }}$ and $E_{\text {min-3shell }}$ (both $p<0.05$ ). Upon comparison of the AUC of $\mathrm{E}_{\text {max-3shell, }}$ $\mathrm{E}_{\text {min-3shell }}$ and the predictive model, significant differences were observed in the AUC (Fig. 5). The logistic regression model significantly improved the diagnostic performance compared to the $\mathrm{E}_{\text {max-3shell }}$ and $\mathrm{E}_{\mathrm{min}-3 \text { shell }}$ alone, with a sensitivity and specificity of 84.9 and $76.7 \%$, respectively.

\section{Observer agreements of SWE features}

The ICC was measured on a scale of 0 to 1 . The observer agreement was divided into three grades: slight agreement $\quad(0.01<\mathrm{ICC}<0.40)$, moderate agreement $(0.40<\mathrm{ICC}<0.75)$, and almost perfect agreement $(0.75<\mathrm{ICC}<1)$. In our study, the intra-observer agreement and inter-observer agreements were almost perfect. The result were shown in Table 3.

\section{Discussion}

In previous studies, it has been shown that qualitative and quantitative SWE parameters can improve the differentiation of benign and malignant breast lesions when employed as an additional sonographic technique $[19,20]$. Some studies had also reported that the peripheral tissue of malignant breast tumors is typically stiffer than inner lesions due to the presence of abnormal stiff collagen associated with cancer fibroblasts, and the infiltration of cancer cells into peri-lesions of the tissue [2123]. Zhou et al. [24] evaluated the presence of the stiff rim sign at $180 \mathrm{kPa}$, and at less than $180 \mathrm{kPa}$, the result showed that for display settings $\leq 180 \mathrm{kPa}$, the stiff rim sign had a higher potential to differentiate between breast lesions. Tozaki and Fukuma [25] had proved Color patterns of 3-dimensional (3D) SWE were useful in the differential diagnosis of breast lesions. Moreover, Chen et al. [26] evaluated 3 views reconstructed by 3D SWE with emphasis on that of transverse, sagittal, and coronal planes. The result revealed that 3D SWE color patterns significantly increased diagnostic accuracy, with the coronal plane of the highest value. However, these studies focused on the stiff rim sign of SWE, without emphasis on the diagnostic performance of different sizes of surrounding tissue (shell) elasticity in the diagnosis of benign and malignant breast lesions. In this study, we applied a shell quantification toolbox feature and proposed quantitative measurements according to the diameter of the shell $(1,2 \& 3 \mathrm{~mm})$. The color range was displayed at $0-140 \mathrm{kPa}$. The results showed that the elastographic values of the shell $\left(\mathrm{E}_{\text {shell }}\right)$ significantly 


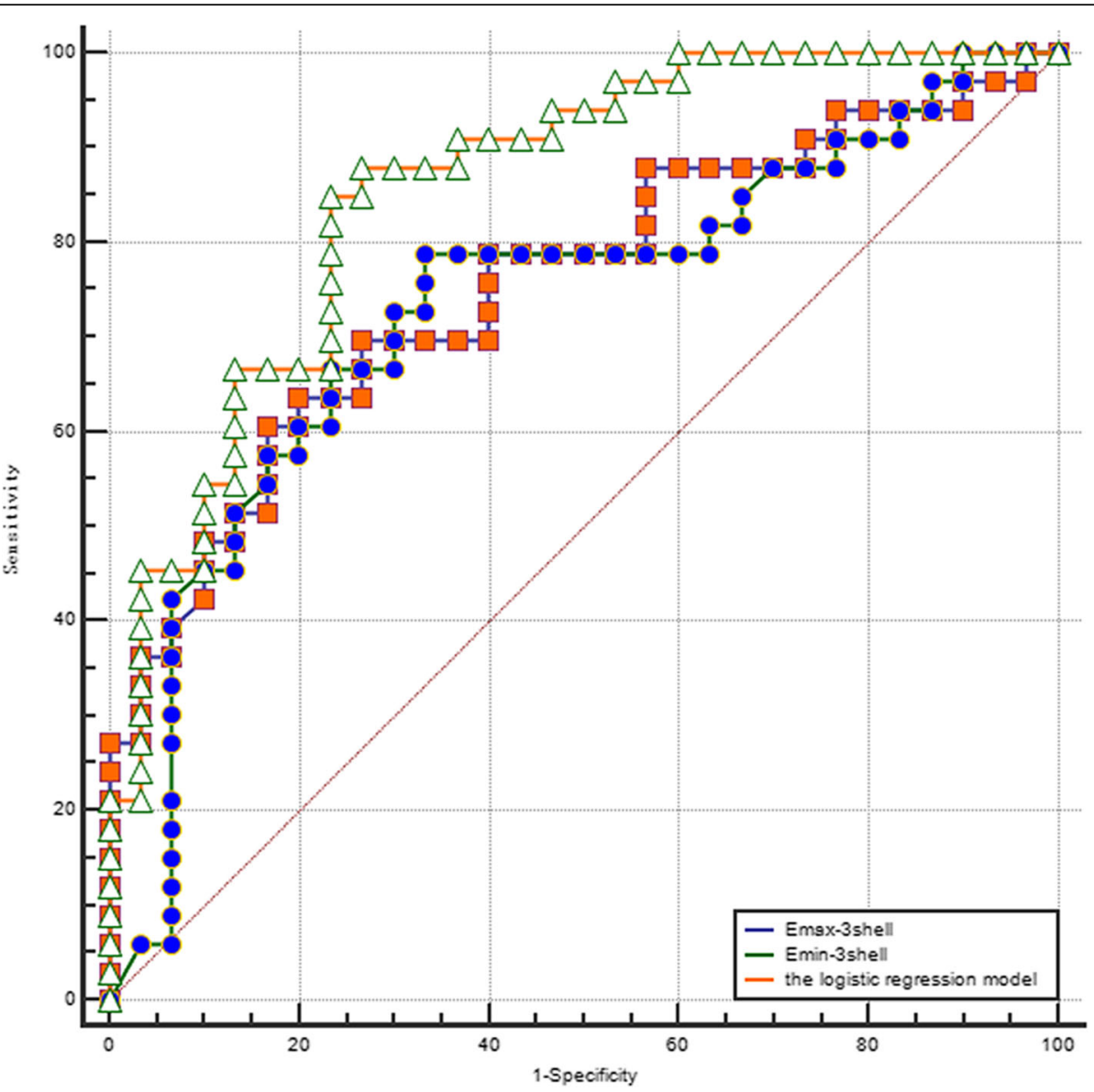

Fig. 5 Receiver operating characteristic curves of the $E_{\max -3 \text { shell }}$ and $E_{\min -3 s h e l l,}$ and logistic regression model values for analyzing the diagnostic performance (AUC of the $E_{\max -3 \text { shell, }} 0.76$; $A \cup C$ of the $E_{\text {min-3shell, }} 0.73$; $A \cup C$ of the logistic regression model values, 0.86)

Table 3 Interobserver and Intraobserver variability of SWE Measurements in Breast Lesions

\begin{tabular}{lll}
\hline & $\begin{array}{l}\text { Interobserver Variability } \\
\text { ICC }\end{array}$ & $\begin{array}{l}\text { Intraobserver Variability } \\
\text { ICC }\end{array}$ \\
\hline$E_{\text {mean-3shell }}$ & 0.83 & 0.90 \\
$E_{\text {max-3shell }}$ & 0.88 & 0.99 \\
$E_{\text {min-3shell }}$ & 0.89 & 0.92 \\
$E_{\text {mean-2shell }}$ & 0.83 & 0.90 \\
$E_{\text {max-2shell }}$ & 0.88 & 0.98 \\
$E_{\text {min-2shell }}$ & 0.88 & 0.95 \\
$E_{\text {mean-15hell }}$ & 0.82 & 0.90 \\
$E_{\text {max-1shell }}$ & 0.87 & 0.98 \\
$E_{\text {min-15hell }}$ & 0.81 & 0.97 \\
$E_{\text {max }}$ & 0.88 & 0.98 \\
$E_{\text {min }}$ & 0.81 & 0.98 \\
\hline
\end{tabular}

differed between benign and malignant breast lesions. Among the elastic parameters, $\mathrm{E}_{\max -3 \text { shell }}$ had a higher AUC (0.76), while no significant differences were observed in the AUCs among the elastic parameters $(p>$ 0.05). Park et al. [27] compared the peritumoral stroma (PS) tissue stiffness of benign and malignant breast lesions by setting multiple rounds $2 \mathrm{~mm}$ ROIs in a linear arrangement onto the inner tumor, tumor-stroma border, and PS. The results indicated that malignant tumors showed a "rapid increase-decrease" pattern and that the maximum elasticity values were observed within proximal PS, which was about $2 \sim 4 \mathrm{~mm}$ from the edge of the tumor. The result was similar to our findings. For this phenomenon, one explanation would be that the peritumoral stiffness was increased because of a desmoplastic reaction or infiltration of cancer cells into the stroma. Another explanation would be that attenuation of the energy of the shear wave in the peritumoral region of the lesion might cause a low shear wave amplitude within the malignant lesion [22, 28]. In previous studies, the $E_{\max }$ and $E_{\text {mean }}$ were the best-performing SWE parameters for differentiating malignant and 
benign breast lesions [29-31]. In this study, the $E_{\text {mean }}$ did not significantly differentiate malignant and benign lesions. The $E_{\text {mean }}$ is equal to the sum of all elasticity values of each pixel divided by the number of pixels within the ROI. The elasticity value is influenced by the size of the ROI [32], which was created manually according to the lesion size using the Mindray ultrasound system. The relative differences in ROI may account for the discrepancies between the studies. Xiao et al. [33] showed that for the logistic regression models, combining the SE features significantly improved diagnostic performance compared to B-mode US. In this study, we proposed a more comprehensive approach, including the analysis of lesion stiffness and surrounding tissue stiffness incorporated into the logistic regression model to discriminate between benign and malignant breast lesions. Univariate analysis showed that the $\mathrm{E}_{\max -3 \text { shell }}$ and $E_{\text {min-3shell }}$ could significantly predict malignant breast lesions. The reliability of the logistic regression model that combined $E_{\max -3 s h e l l}$ and $E_{\min -3 s h e l l}$ was confirmed by the AUC of 0.86, which was higher than the individual AUC of the $E_{m a x}$-3shell and $E_{\text {min-3shell. }}$. Compared to the AUC of the $E_{\text {max-3shell }}, E_{\text {min-3shell }}$ and the predictive model, significant differences were observed. The logistic regression model had a higher diagnostic performance for benign and malignant breast lesions. Using the cut-off value of $E_{\text {max-3shell }}(156.96 \mathrm{kPa})$ and $E_{\text {min-3shell }}(3.99 \mathrm{kPa})$ as discriminative parameters, the negative predictive values for malignancy were only 65.79 and $66.67 \%$, respectively. The logistic regression analysis showed that the negative predictive value was $71.9 \%$, which was improved. Vinnicombe et al. [34] demonstrated that in situ ductal carcinomas (DCIS) were likely to display benign shear wave features. However, in our study, only a single (20\%; 1/5) DCIS showed false-negative findings by using the logistic regression model. This phenomenon showed that the logistic regression model might contribute to an improvement in diagnostic accuracy for DCIS. However, since the number of cases included in this study is small, more cases will be needed for verification in the future. While in this study, 8 malignant lesions were still falsenegatives $(24.2 \% ; 8 / 33)$, in 8 of the false-negative cases, 4 had a lesion size $\leq 15 \mathrm{~mm}$ and 1 had a lesion size $\leq 10$ $\mathrm{mm}$. Previous studies had shown that malignancies $\leq 15$ $\mathrm{mm}$ and/or $\leq 10 \mathrm{~mm}$ tend to show benign features leading to false results [22].

There were some limitations to this study. Firstly, a small sample size is a limitation of the present study. Breast nodules are common disease in clinical, a total of 178 consecutive patients with breast lesions who underwent the conventional US and SWE examination were selected in this study. However, for the exclusive reasons, only 63 patients were finally enrolled in this study. Secondly, we did not assess the diagnostic performance of ultrasound features combined with BI-RADS, meanwhile, lesions with BI-RADS scores less than 3 based on the conventional US were excluded in this study, which may result in selection bias. Finally, factors influencing the elastic characteristics of the surrounding tissues, including lesion depth, breast density and pre-compression, were not evaluated.

\section{Conclusion}

$\mathrm{E}_{\text {shell }}$ values are highly correlative to malignant breast lesions. SWE features, particularly the combination of $E_{\max -3 s h e l l}$ and $E_{\min -3 s h e l l}$ can improve the differentiation of breast lesions. The logistic regression model enabled the correct differentiation of benign and malignant breast lesions with a sensitivity of $84.9 \%$ and a specificity of $76.7 \%$. The diagnostic performance of this model exceeded that of the elastographic parameters of $E_{\text {shell }}$ and $\mathrm{E}$ alone when evaluating benign and malignant breast lesions.

\section{Abbreviations \\ SWE: Shear wave elastography; AUC: The area under the receiver operating characteristic curve; US: Ultrasonography; ACR: The American College of Radiology; SE: Strain elastography; ROI: Region of interest; ICCs: Intraclass correlation coefficients; OR: Odds ratio; DCIS: Ductal carcinoma in situ; QCC: Quality control chart; SD: Standard deviation; TP: True positive; FP: False positive; TN: True negative; FN: False negative}

\section{Acknowledgements}

Not applicable.

\section{Authors' contributions}

Study concept and design: PT $H$. Acquisition of data: $H Y, Y Y X, Y N Z, J Y$, and $\mathrm{PT} H$. Analysis and interpretation of data: $H Y, Y Y X, Y N Z, J Y$, and PT $H$. Drafting of the manuscript: $H Y, P T H$. Performing conventional ultrasound and elastography examinations: $Y Y X$. Critical revision of the manuscript for important intellectual content: PT H. Statistical analysis: H Y, PT H. Manuscript modification: ZY C, PT H. All authors have read and approved the manuscript.

\section{Funding}

This study was supported by the National Natural Science Foundation of China (NO. 81527803, 81420108018, 81671707), the National Key Research and Development Program of China (No. SQ2018YFC010090), Zhejiang Science and Technology Project (2019C03077), Natural Science Foundation of Guangdong Province (No. 2016A030311054). The funders had no role in the study design, data collection and analysis, decision to publish or preparation of the manuscript.

\section{Availability of data and materials}

The datasets used and/or analyzed in the current study are available from the corresponding author upon request.

\section{Ethics approval and consent to participate}

All procedures performed in studies involving human participants were in accordance with the ethical standards of the Second Affiliated Hospital of Zhejiang University (Zhejiang, China), and with the 1964 Helsinki declaration and its later amendments or comparable ethical standards. The experiments complied with the current laws of China. Written informed consent was obtained from all participants in the study.

\section{Consent for publication}

Written informed consent was obtained from patients for publication of this article and accompanying images. A copy of the written consent is available for review by the Editor-in Chief of BMC cancer. 


\section{Competing interests}

The authors declare no conflicts of interest.

\section{Author details}

'Department of Ultrasound in Medicine, The Second Affiliated Hospital of Zhejiang University School of Medicine, Hangzhou 310009, China. 2Department of Ultrasound Medicine, Laboratory of Ultrasound Molecular Imaging, The Third Affiliated Hospital of Guangzhou Medical University, The Liwan Hospital of the Third Affiliated Hospital of Guangzhou Medical University, Guangzhou 510000, Guangdong, China.

Received: 31 October 2019 Accepted: 16 September 2020 Published online: 29 September 2020

\section{References}

1. Basu P, Selmouni F, Belakhel L, Abousselham L, Lucas E, Muwonge R, Sankaranarayanan R, Khazraji YC. Breast Cancer screening program in Morocco: status of implementation, organization and performance. Int J Cancer. 2018;143(12):3273-80.

2. Yu Y, Xiao Y, Cheng J, Chiu B. Breast lesion classification based on supersonic shear-wave elastography and automated lesion segmentation from B-mode ultrasound images. Comput Biol Med. 2018;1(93):31-46.

3. Kim EK, Ko KH, Oh KK, Kwak JY, You JK, Kim MJ, Park BW. Clinical application of the BI-RADS final assessment to breast sonography in conjunction with mammography. AJR Am J Roentgenol. 2008;190(5):1209-15.

4. Hong S, Woo OH, Shin HS, Hwang SY, Cho KR, Seo BK. Reproducibility and diagnostic performance of shear wave elastography in evaluating breast solid mass. Clin Imaging. 2017:44:42-5.

5. Lee SH, Chang JM, Kim WH, Bae MS, Seo M, Koo HR, Chu AJ, Gweon HM, Cho N, Moon WK. Added value of shear-wave elastography for evaluation of breast masses detected with screening US imaging. Radiology. 2014; 273(1):61-9

6. Berg WA, Blume JD, Cormack JB, Mendelson EB, Lehrer D, Böhm-Vélez M, Pisano ED, Jong RA, Evans WP, Morton MJ, et al. Combined screening with ultrasoundand mammography vs mammography alone in women at elevated risk of breast cancer. JAMA. 2008;299(18):2151-63.

7. Gong X, Xu Q, Xu Z, Xiong P, Yan W, Chen Y. Real-time elastography for the differentiation of benign and malignant breast lesions: a meta-analysis. Breast Cancer Res Treat. 2011:130(1):11-8.

8. Sadigh G, Carlos RC, Neal CH, Dwamena BA. Ultrasonographic differentiation of malignant from benign breast lesions: a meta-analytic comparison of elasticity and BIRADS scoring. Breast Cancer Res Treat. 2012;133(1):23-35.

9. Sadigh G, Carlos RC, Neal CH, Dwamena BA. Accuracy of quantitative ultrasound elastography for differentiation of malignant and benign breast abnormalities: a meta-analysis. Breast Cancer Res Treat. 2012;134(3):923-31.

10. Barr RG, Destounis S, Lackey LB, Svensson WE, Balleyquier C, Smith C. Evaluation of breast lesions using sonographic elasticity imaging: a multicenter trial. J Ultrasound Med. 2012;31(2):281-7.

11. Destounis $S$, Arieno A, Morgan R, Murphy P, Seifert $P$, Somerville $P$, Young W. Clinical experience with elasticity imaging in a community-based breast center. J Ultrasound Med. 2013;32(2):297-302.

12. Piccoli CW, Forsberg F. Advanced ultrasound techniques for breast imaging. Semin Roentgenol. 2011;46:60-7.

13. Yoon JH, Kim MH, Kim EK, Moon HJ, Kwak JY, Kim MJ. Interobserver variability of ultrasound elastography: how it affects the diagnosis of breast lesions. AJR Am J Roentgenol. 2011;196(3):730-6.

14. Chang JM, Moon WK, Cho N, Kim SJ. Breast mass evaluation: factors influencing the quality of US elastography. Radiology. 2011;259(1):59-64.

15. Choi HY, Sohn YM, Seo M. Comparison of $3 D$ and $2 D$ shear-wave elastography for differentiating benign and malignant breast masses: focus on the diagnostic performance. Clin Radiol. 2017;72(10):878-86

16. Cosgrove DO, Berg WA, Doré CJ, Skyba DM, Henry JP, Gay J, Cohen-Bacrie C. Shear wave elastography for breast masses is highly reproducible. Eur Radiol. 2012;22(5):1023-32.

17. Xiao Y, Yu Y, Niu L, Qian M, Deng Z, Qiu W, Zheng H. Quantitative evaluation of peripheral tissue elasticity for ultrasound-detected breast lesions. Clin Radiol. 2016;71(9):896-904.

18. Lee EJ, Jung HK, Ko KH, Lee JT, Yoon JH. Diagnostic performances of shear wave elastography: which parameter to use in differential diagnosis of solid breast masses ? Eur Radiol. 2013;23(7):1803e11.
19. Youk JH, Gweon HM, Son EJ. Shear-wave elastography in breas ultrasonography: the state of the art. Ultrasonography. 2017;36(4):300-9.

20. Seo M, Ahn HS, Park SH, Lee JB, Choi BI, Sohn YM, Shin SY. Comparison and combination of strain and shear wave Elastography of breast masses for differentiation of benign and malignant lesions by quantitative assessment: preliminary study. J Ultrasound Med. 2018:37(1):99-109.

21. Evans A, Whelehan P, Thomson K, McLean D, Brauer K, Purdie C, Baker L, Jordan $L$, Rauchhaus $P$, Thompson A. Invasive breast cancer relationship between shear-wave elastographic findings and histologic prognostic factors. Radiology. 2012;263(3):673-7.

22. Evans A, Whelehan P, Thomson K, McLean D, Brauer K, Purdie C, Jordan L, Baker L, Thompson A. Quantitative shear wave ultrasound elastography: initia experience in solid breast masses. Breast Cancer Res. 2010;12(6):R104.

23. Tozaki M, Fukuma E. Pattern classification of shear wave Elastography images for differential diagnosis between benign and malignant solid breast masses. Acta Radiol. 2011;52:1069-75.

24. Zhou J, Zhan W, Chang C, Zhang X, Jia Y, Dong Y, Zhou C, Sun J, Grant EG. Breast lesions: evaluation with shear wave elastography, with special emphasis on the "stiff rim" sign. Radiology. 2014;272(1):63-72.

25. Tozaki M, Fukuma E. Pattern classifification of shear wave Elastography images for differential diagnosis between benign and malignant solid breast masses. Acta Radiol . 2011; 52:1069-1075.

26. Chen YL, Chang C, Zeng W, Wang F, Chen JJ, Qu N. 3-dimensional shear wave elastography of breast lesions: added value of color patterns with emphasis on crater sign of coronal plane. Medicine (Baltimore). 2016;95(39): e4877.

27. Park HS, Shin HJ, Shin KC, Cha JH, Chae EY, Choi WJ, Kim HH. Comparison of peritumoral stromal tissue stiffness obtained by shear wave elastography between benign and malignant breast lesions. Acta Radiol. 2018;59(10): 1168-75.

28. Itoh A, Ueno E, Tohno E, Kamma H, Takahashi H, Shiina T, Yamakawa M, Matsumura T. Breast disease: clinical application of US elastography for diagnosis. Radiology. 2006;239:341-50.

29. Shiina T, Nightingale KR, Palmeri ML, Hall TJ, Bamber JC, Barr RG, Castera L, Choi BI, Chou YH, Cosgrove D, et al. WFUMB guidelines and recommendations for clinical use of ultrasound elastography: part 1: basic principles and terminology. Ultrasound Med Biol. 2015;41(5):1126-47.

30. Song EJ, Sohn YM, Seo M. Diagnostic performances of shear-wave elastography and B-mode ultrasound to differentiate benign and maligna3nt breast lesions: the emphasis on the cutoff value of qualitative and quantitative parameters. Clin Imaging. 2018;50:302-7.

31. Çebi Olgun D, Korkmazer B, Kılıç F, Dikici AS, Velidedeoğlu M, Aydoğan F, KantarcI F, Y.Imaz MH. Use of shear wave elastography to differentiate benign and malignant breast lesions. Diagn Interv Radiol. 2014;20(3):23944

32. Skerl K, Vinnicombe S, Thomson K, McLean D, Giannotti E, Evans A. Anisotropy of solid breast lesions in 2D shear wave elastography is an indicator of malignancy. Acad Radiol. 2016:23:53-61.

33. Xiao Y, Zeng J, Zhang X, Niu LL, Qian M, Wang CZ, Zheng HR, Zheng RQ. Ultrasound strain Elastography for breast lesions: computer-aided evaluation with quantifiable Elastographic features. J Ultrasound Med. 2017;36(6):1089100.

34. Vinnicombe SJ, Whelehan P, Thomson K, McLean D, Purdie CA, Jordan LB, Hubbard S, Evans AJ. What are the characteristics of breast cancer misclassified as benign by quantitative ultrasound shear wave elastography? Eur Radiol. 2014;24(4):921-6.

\section{Publisher's Note}

Springer Nature remains neutral with regard to jurisdictional claims in published maps and institutional affiliations. 